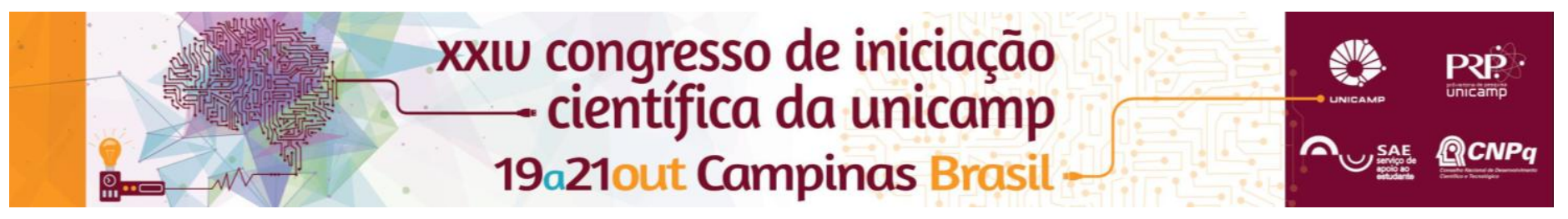

\title{
Utilização de série temporal MODIS/NDVI para mapeamento de pastagem
}

\author{
Lívia F. Defeo*, Jansle V. Rocha, Victor D. Manabe, Márcio R. S. Melo
}

\section{Resumo}

Apesar da importância da bovinocultura na economia brasileira, a mesma vem perdendo espaço para a produção de outras commodities agrícolas, como a soja e a cana-de-açúcar. Além disso, estudos apontam que a expansão dessas atividades tem sido sobre pastagens degradadas. $\mathrm{O}$ objetivo desse trabalho é avaliar dados de séries temporais de índices de vegetação, por meio de técnicas de sensoriamento remoto a fim de otimizar o monitoramento da pastagem. Os resultados mostraram a utilização do NDVI como a melhor escolha dentre os dados avaliados para um posterior mapeamento da pastagem.

\section{Palavras-chave:}

Sensoriamento remoto, índice de vegetação, uso e cobertura da terra.

\section{Introdução}

A bovinocultura apresenta posição de destaque entre as atividades agropecuárias no Brasil. No entanto, vem perdendo área para a produção de outras commodities. Pesquisas apontam que a expansão destas atividades tem sido majoritariamente sobre áreas de pastagens degradadas. A redução dessas áreas tem provocado a intensificação do uso de pastagens remanescentes e a maximização de seus recursos. Nessa perspectiva, a utilização de séries temporais de índices de vegetação possibilita a identificação e o mapeamento de pastagens e cultivos agrícolas, uma vez que permitem a diferenciação dos alvos em função da variação da resposta espectral dos mesmos ao longo do tempo.

O sensor MODIS a bordo das plataformas Terra e Aqua, conta com dois produtos de índices de vegetação, o NDVI (Normalized Difference Vegetation Index) e o EVI (Enhanced Vegetation Index).

O presente trabalho tem como objetivo a identificação de métricas fenológicas e seus respectivos parâmetros para caracterização da pastagem para as mesorregiões de Araçatuba e São José do Rio preto, no estado de São Paulo, através de dados temporais de índices de vegetação.

\section{Resultados e Discussão}

A primeira etapa do presente projeto foi a obtenção das imagens do sensor MODIS de índices de vegetação (NDVI e EVI), a partir do banco de dados da Embrapa Informática Agropecuária - CNPTIA, além da confecção um mosaico composto por imagens Landsat 8 do estado de São Paulo no período entre Agosto/2012 e Julho/2013. Foram utilizados pontos de cana-de-açúcar e pastagem para a extração de dados temporais de índices de vegetação nas imagens MODIS, sendo parte obtida em campo, nas mesorregiões de Araçatuba e São José do Rio Preto e, parte através da interpretação visual do mosaico elaborado. No total foram utilizados 401 pontos de cana e 386 pontos de pastagem.

A partir dos dados citados anteriormente, juntamente com técnicas de filtragem (Savitzky-Golay e Hants) e rotinas de métricas fenológicas (Máximos e Mínimos e Coeficiente Angular), foi obtido o banco de dados trabalhado no projeto (Fontana et al., 2007; Moraes, 2012)

As imagens passaram por uma classificação qualitativa através de técnicas de mineração de dados (árvore de decisão), e então foi possível a avaliação dos resultados.

Tabela 1. Resultados obtidos com a mineração de dados

\begin{tabular}{|c|c|c|c|}
\hline $\begin{array}{c}\text { Índice de } \\
\text { Vegetação }\end{array}$ & Filtragem & Rotina & $\begin{array}{c}\text { Exatidão } \\
\text { Global (\%) }\end{array}$ \\
\hline \multirow{6}{*}{ NDVI } & \multirow{3}{*}{ Hants } & Coef. Angular & 78,53 \\
\hline & & $\begin{array}{c}\text { Máximos e } \\
\text { Mínimos }\end{array}$ & 81,96 \\
\hline & & Todas & 83,48 \\
\hline & \multirow{3}{*}{$\begin{array}{l}\text { Savitzky- } \\
\text { Golay }\end{array}$} & Coef. Angular & 80,31 \\
\hline & & $\begin{array}{l}\text { Máximos e } \\
\text { Mínimos }\end{array}$ & 78,78 \\
\hline & & Todas & 86,15 \\
\hline \multirow{6}{*}{ EVI } & \multirow{3}{*}{ Hants } & Coef. Angular & 72,17 \\
\hline & & $\begin{array}{c}\text { Máximos e } \\
\text { Mínimos }\end{array}$ & 77,38 \\
\hline & & Todas & 79,54 \\
\hline & \multirow{3}{*}{$\begin{array}{l}\text { Savitzky- } \\
\text { Golay }\end{array}$} & Coef. Angular & 72,68 \\
\hline & & $\begin{array}{c}\text { Máximos e } \\
\text { Mínimos }\end{array}$ & 76,36 \\
\hline & & Todas & 80,38 \\
\hline
\end{tabular}

\section{Conclusões}

Verificou-se que para a metodologia proposta, o conjunto de dados que apresentou melhor desempenho diferenciação entre pastagem e cana-de-açúcar, foi o conjunto de imagens de série temporal de NDVI, obtidas através das plataformas Terra e Aqua, filtradas pelo método Savitzy-Golay com dados das rotinas de Máximos e Mínimos e Coeficiente Angular.

A obtenção de uma metodologia eficaz de diferenciação da pastagem pode auxiliar estudos futuros, em que seja necessário fazer a diferenciação entre áreas de pastagem e cana, para a região estudada no trabalho.

\section{Agradecimentos}

Gostaria de agradecer ao CNPq e ao Laboratório de Geoprocessamento da Unicamp pela oportunidade de desenvolver essa pesquisa. Agradeço também ao Professor Jansle, Victor e Márcio pela orientação dada.

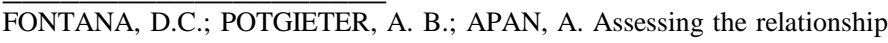
between shire winter crop yield and seasonal variability of the MODIS NDVI and EVI images. Applied GIS, Victoria, v. 3, n. 1, p. 1 -16, 2007.

MORAES, R. A. Monitoramento e estimativa da produção da cultura de cana-de-açúcar no estado de São Paulo por meio de dados espectrais e agrometeorológicos. Tese (Doutorado em Engenharia Agrícola), Faculdade de Engenharia Agrícola. Universidade Estadual de Campinas. Campinas, SP: [s.n.], 2012 